\title{
Identification of Quantitative Trait Loci (QTLs) Conferring Dry Matter Content and Starch Content in Cassava (Manihot esculenta Crantz)
}

\author{
Vidya Prasannakumari", Aswathy Gopalakrishnan Heinining Nair, Chokkappan Mohan \\ Division of Crop Improvement ICAR-Central Tuber Crops Research Institute (ICAR-CTCRI), Sreekariyam, Thiruvananthapuram, India
}

Email address:

vidyapemail@gmail.com (V. Prasannakumari), aswathyghnair07@gmail.com (A. G. H. Nair), cmsan99@gmail.com (C. Mohan)

${ }^{*}$ Corresponding author

\section{To cite this article:}

Vidya Prasannakumari, Aswathy Gopalakrishnan Heinining Nair, Chokkappan Mohan. Identification of Quantitative Trait Loci (QTLs)

Conferring Dry Matter Content and Starch Content in Cassava (Manihot esculenta Crantz). American Journal of BioScience.

Vol. 9, No. 1, 2021, pp. 1-9. doi: 10.11648/j.ajbio.20210901.11

Received: November 25, 2020; Accepted: December 9, 2020; Published: January 18, 2021

\begin{abstract}
Cassava tubers are an excellent source of carbohydrate and a competitive source of starch most traded internationally. It is a highly desirable raw material for food and industrial purpose due to its high dietary carbohydrate content. The economic value of cassava products lies in the DMC (dry matter content). Cassava roots contain up to 80-90 per cent of carbohydrate by dry weight and 80 per cent of carbohydrate is starch. Increasing world population, limited land area, changing climatic condition and food scarcity demanded the need for improved cassava starch. Yield of cassava tubers is related to both tuber volume and DMC and thus DMC can be improved by cassava breeding. Thus QTL mapping of DMC is very much relevant to understand the genetic effects controlling the traits. The current study focused on QTL mapping for DMC and SC (starch content) to identify and study the favourite alleles using Windows cartographer version 2.5. Single marker analysis (SMA) identified seven marker alleles associated with DMC and eight marker alleles associated with SC. Using interval mapping, a single QTL for DMC was identified in chrom21 flanked by SSRY $110^{\mathrm{b}}$ and SSRY $182^{\mathrm{b}}$. On the other hand, five QTLs for SC were identified by simple interval mapping (SIM) and a single QTL in chrom 17 with $\mathrm{R}^{2}$ value of $12 \%$ and at a LOD value 5 using composite interval mapping (CIM). The exact position of the QTLs and its interactions were studied using MIM and the genetic effect of QTLs controlling DMC was found to be over-dominance. But in the case of SC, the QTL interaction was identified and found to be additive $\mathrm{x}$ additive epistatic interaction.
\end{abstract}

Keywords: Cassava, Dry Matter Content, Linkage Map, Quantitative Trait Loci, Starch Content

\section{Introduction}

Cassava is an important tuber crop and a highly desirable raw material for food and industrial purpose due to its high dietary carbohydrate content feeding more than 800 million people [8]. According to Food and Agriculture Organization Corporate Statistical Database FAOSTAT [21], the global cassava production was estimated to be $277.8 \mathrm{MT}$ and the Indian production was accounted to be 4651000 ton from an area of 228000 ha. Cassava usage varied significantly by region and about 60 to $70 \%$ of cassava produced globally is used for food and $40 \%$ of the total cassava production is used for starch extraction [23]. Apart from food, cassava starch and its derivatives are used in the making of confectionery, sweeteners, glues, plywood, textiles, paper, biodegradable products, monosodium glutamate and drugs. Cassava chips and pellets are used in making animal feed and alcohol production.

Cassava is a starchy root crop grown in small-scale by farmers and large-scale by industries due to the high demand for starch. Starch content (SC) and dry matter (DM) were two important parameters that affect the use of cassava as food and an industrial raw material [24]. On an average, Cassava tuber contains about $70 \%$ moisture, $20-30 \%$ carbohydrate, $1.0-1.8 \%$ crude protein, $1.5-3.5 \%$ crude fiber, $0.35-0.45 \%$ fat and $8-28 \mathrm{mg} \mathrm{HCN} / \mathrm{kg}$ of dry mass [18]. Kawuki et al. [31] reported a wide genetic variability for DMC in Africa. DMC was affected by a number of genetic and environmental factors include age of the plant, crop 
season, location and efficiency of canopy to trap sunlight [36]. It was usually highest before the onset of rain and dropped after the rain. This was due to the mobilization of starch from root to leaves in order to establish re-growth [9]. Allocation of DM to the storage root varied with the growth stages and DM was almost zero during the early stages to 80 per cent during the late growth stage [1]. Micronutrients in cassava is very low and several researches were carried in the cassava tubers to improve the micronutrient content such as provitamin A [7]. Biofortification of cassava largely depends on various agronomic parameters such as starch content, DMC, resistance to diseases and pests etc. DMC is one such parameters influences the cassava tuber texture after boiling and it is also studied that there is no negative relationship between carotenoids and DMC [15].

The storage root is a key organ for the direct production of cassava which contains high amount calories, but low protein, fat, mineral and vitamin content. Eighty per cent of carbohydrate in cassava is starch and 80-90 per cent carbohydrate is contributed by dry weight Wanatsanam et al., [57]. Starch is the main storage carbohydrate synthesized from sucrose, inside amyloplast. This starchy root crops have becomes a significant feed stock for both food and commodity industries besides rice and cereals. With the increasing world population, extremely unpredictable environmental condition, limiting land area for cultivation and food scarcity strengthened the need for the development of new cassava cultivars with improved starch through cassava breeding program. Two main factors that determine the yield of cassava tubers are tuber volume and dry matter content. Yield therefore can be improved by increasing the dry matter content which itself reflects the economic value of cassava products Teye et al., [53]. Significant correlation exists between starch and dry matter content in storage roots were reported by Cervantes-Flores et al., [16]. Transcriptomic data integration of starch biosynthesis indicated that the genes involved in starch biosynthesis are more up-regulated and the carbon source for biosynthesis is from D-glucose-1-phosphate (G1P) Wanatsanam et al., [57]. QTL mapping of such complex traits is very much relevant to identify the favorable alleles and to understand the genetic effects controlling the traits. With this in mind, the present study focused to identify QTLs controlling DMC and SC in cassava using $F_{1}$ mapping population derived from a cross between MNga-1 and CI-732.

\section{Materials and Methods}

In this study, two cassava cultivars viz., CI-732 (local variety with high DMC and SC) and MNga-1 (CMD resistant variety with low DMC and SC) were selected as female and male parents based on the field trials conducted in ICARcentral Tuber Crops Research Institute (ICAR-CTCRI) during 2011-2015. The two cultivars were contrasted in $\mathrm{DMC}, \mathrm{SC}$, tuber skin colour, tuber rind colour and tuber flesh colour. CI-732 produced tubers with brown coloured skin, pink coloured rind and cream coloured flesh. On the other hand, MNga-1 produced tubers with ivory coloured skin, white coloured rind and white coloured flesh. The parental lines were crossed and produced $114 \mathrm{~F}_{1}$ progenies named as KM-1 to KM-114. The DMC and SC in the parental lines and $\mathrm{F}_{1}$ progenies were determined by both oven dry method and by using electronic balance.

\subsection{Phenotypic Evaluation}

\subsubsection{Determination of Dry Matter Content Using Dry Oven Method}

The dry matter content in newly harvested cassava tubers of first clonal trials was analyzed by oven dry methods. In this method, a total of $50 \mathrm{~g}$ of fresh peeled cassava tubers obtained from three different sections (head, middle and tail) were chopped into small pieces was dried at $60^{\circ} \mathrm{C}$ for $72 \mathrm{~h}$ in an oven. Each $F_{1}$ genotype was replicated three times and weight of dried sample was expressed as percentage of fresh weight [4].

$$
\operatorname{Dry} \text { matter }(\%)=\frac{\text { weight of dried sample }(g)}{\text { weight of fresh sample }(g)} \times 100
$$

\subsubsection{Determination by Starch Content Using Electronic Balance}

The starch content in newly harvested cassava tubers were performed by electronic balance. Firstly, the tubers were properly cleaned in water to remove the soil particles. With clean water, lift the bucket to the empty basket until the basket is completely immersed in water. Weighed the empty basket immersed in water and recorded the weight of basket indicated by the device. Lift the bucket back to the lower position. Weighed 3-6 kg clean cassava tubers into the basket in air. Lift the bucket to the basket containing cassava tubers until the basket was completely immersed in water and weighed again. Starch content of the sampling was calculated by a microprocessor in the indicating device. The SC was calculated automatically by microprocessor attached with the indicating device using the formula

$$
\text { Starch content }(S C)=\frac{(S G-1.00906)}{0.004845} \%
$$

Where, $\mathrm{SG}$ is the specific gravity

Analysis of variance (ANOVA) was performed for DMC and SC and the means were compared with DUNCAN's multiple range test. The correlation study between DMC and $\mathrm{SC}$ was also performed.

\subsection{QTL Mapping}

The QTL mapping of DMC and SC of $\mathrm{F}_{1}$ progenies was done separately to find out the markers associated with the particular traits using the genetic linkage map already constructed [56]. The QTL mappings were carried out using three different methods viz., single marker analysis (SMA), simple interval mapping (SIM), composite interval mapping (CIM) and multiple interval mapping (MIM) in Windows QTL Cartographer version 2.5. A significant LOD value for a particular trait in interval mapping was decided by the genome- 
wide significant threshold value which itself was calculated by means of permutation test carried out at 1000 replicates, 5\% level of significance and at a walk speed of 1cM [35]. CIM was performed using the parameters viz., forward and backward regression, Model-6 standard model, 10 control markers and a walk speed of $1 \mathrm{cM}[26,27,61,62]$ The Broad-sense heritability $\left(\mathrm{H}^{2}\right)$ of the trait was calculated using the formula

$$
\mathrm{H}^{2}=\frac{\mathrm{V}_{\mathrm{G}}}{\mathrm{V}_{\mathrm{P}}} \times 100
$$

$\mathrm{V}_{\mathrm{G}}$ is the total genetic variance (additive, dominant and epistatic) and $V_{P}$ is the total phenotypic variance

The narrow sense heritability $\left(\mathrm{h}^{2}\right)$ of the QTLs for a particular trait was calculated using the formula

$$
\mathrm{h}^{2}=\frac{\mathrm{V}_{\mathrm{A}}}{\mathrm{V}_{\mathrm{P}}} \times 100
$$

$V_{A}$ is the total additive variance and $V_{P}$ is the total phenotypic variance

The expected advance or gain from the current breeding population were calculated using the formula

$$
\mathrm{G}_{\mathrm{c}}=(k)\left(\sqrt{V_{P}}\right) h^{2}
$$

$\mathrm{G}_{\mathrm{c}}=$ genetic advance or gain, $\sqrt{V_{P}}=$ square root of phenotypic variance, $k=$ Selection intensity $(1.76), \mathrm{h}^{2}=$ narrow sense heritability

\section{Result and Discussion}

Cassava tubers are an excellent source of carbohydrate and a competitive source of starch most traded internationally. The increasing demand for starch established the large-scale commercial planting of cassava. The economic value for cassava products lies in the DMC and is regarded as the true biological yield. The yield of cassava tubers can be improved by cassava breeding programmes. In the current study, DMC in parental lines and $\mathrm{F}_{1}$ mapping population were analyzed by oven dry method. DMC of male and female parent was found to be $38 \%$ and $54 \%$ respectively. The DMC of $\mathrm{F}_{1}$ progenies were also taken and found that out of the 114 individuals, 21 individuals showed DMC below 40, 28 individuals with a DMC between 40 and 45, 45 individuals between 46 and 50 and 20 progenies showed DMC above 50. The high DMC ranging from 58-55 was observed in four progenies named KM-2B (57.41), KM-83 (56.32), KM-103 (56.15) and KM-32 (55.78). These genotypes were found statistically significant from other genotypes. The mean trait value was found to be 45.07 with a variance of $35.75 \%$. The distribution of DMC among $F_{1}$ progenies were skewed towards high DMC (above $45 \%$ ) indicating the influence of female parent.

The SC of parental lines viz., MNga-1 and CI-732 were analyzed in electronic balance and was found to be 21 and 27 respectively. The mean trait value of the $\mathrm{SC}$ was found to be 24.43 with a variance of $19.7 \%$. In this study, 53 individuals showed SC falls between 26 and 30, 38 individuals with SC between 21 and 25, five individuals showed SC above 30 and 20 individuals with SC below 20. The SC was found to be highest in genotype KM-32 (33) and was on par with KM-23 (30.5), KM-24 (30.5) and KM-25 (31). The positive correlation between DMC and SC was found to be $\mathrm{r}=0.735$

\begin{tabular}{|c|c|c|c|c|c|c|c|c|}
\hline Sl. No. & DMC & SC & Sl. No. & DMC & $\mathrm{SC}$ & Sl. No. & DMC & SC \\
\hline 1 & 44.19 & 25.0 & 39 & 50.20 & 26.0 & 77 & 31.09 & 18.0 \\
\hline 2 & 50.43 & 27.4 & 40 & 43.48 & 26.5 & 78 & 45.59 & 30.0 \\
\hline 3 & 57.41 & 28.0 & 41 & 49.27 & 25.5 & 79 & 35.20 & 12.0 \\
\hline 4 & 41.32 & 22.0 & 42 & 52.15 & 28.5 & 80 & 41.80 & 19.0 \\
\hline 5 & 52.56 & 27.0 & 43 & 41.34 & 23.5 & 81 & 56.11 & 29.5 \\
\hline 6 & 25.60 & 12.0 & 44 & 45.14 & 26.0 & 82 & 49.23 & 23.5 \\
\hline 7 & 36.72 & 17.0 & 45 & 34.50 & 15.0 & 83 & 41.12 & 22.0 \\
\hline 8 & 50.43 & 28.0 & 46 & 40.83 & 21.0 & 84 & 49.18 & 29.0 \\
\hline 9 & 45.16 & 25.5 & 47 & 45.70 & 26.5 & 85 & 40.36 & 25.0 \\
\hline 10 & 50.69 & 27.5 & 48 & 47.05 & 26.0 & 86 & 33.18 & 18.0 \\
\hline 11 & 48.28 & 28.5 & 49 & 44.36 & 25.0 & 87 & 38.00 & 19.5 \\
\hline 12 & 43.11 & 22.5 & 50 & 33.80 & 13.5 & 88 & 48.81 & 26.5 \\
\hline 13 & 48.15 & 29.0 & 51 & 47.93 & 24.0 & 89 & 38.30 & 15.0 \\
\hline 14 & 45.00 & 22.0 & 52 & 42.07 & 25.0 & 90 & 51.71 & 29.0 \\
\hline 15 & 50.22 & 26.5 & 53 & 50.02 & 23.0 & 91 & 37.43 & 18.0 \\
\hline 16 & 38.81 & 26.0 & 54 & 48.68 & 23.0 & 92 & 48.27 & 27.5 \\
\hline 17 & 45.14 & 21.0 & 55 & 37.01 & 28.5 & 93 & 47.06 & 20.0 \\
\hline 18 & 48.48 & 30.5 & 56 & 49.13 & 26.0 & 94 & 40.78 & 26.5 \\
\hline 19 & 49.69 & 30.5 & 57 & 47.56 & 23.5 & 95 & 39.52 & 26.5 \\
\hline 20 & 49.14 & 31.0 & 58 & 50.31 & 26.0 & 96 & 43.14 & 24.0 \\
\hline 21 & 54.55 & 30.0 & 59 & 49.79 & 26.5 & 97 & 43.60 & 22.0 \\
\hline 22 & 55.74 & 33.0 & 60 & 52.60 & 28.5 & 98 & 35.59 & 23.0 \\
\hline 23 & 38.23 & 22.0 & 61 & 41.47 & 24.0 & 99 & 30.47 & 17.0 \\
\hline 24 & 47.56 & 27.5 & 62 & 49.34 & 27.5 & 100 & 48.58 & 28.0 \\
\hline 25 & 50.90 & 27.5 & 63 & 44.83 & 22.5 & 101 & 39.32 & 15.0 \\
\hline 26 & 48.57 & 25.5 & 64 & 48.07 & 27.0 & 102 & 42.63 & 21.5 \\
\hline 27 & 49.56 & 26.5 & 65 & 45.82 & 20.0 & 103 & 55.10 & 28.5 \\
\hline
\end{tabular}
(Table 1).

Table 1. DMC and SC of $F_{1}$ progenies derived from MNga-1/CI-732. 


\begin{tabular}{|c|c|c|c|c|c|c|c|c|}
\hline Sl. No. & DMC & SC & Sl. No. & DMC & SC & Sl. No. & DMC & SC \\
\hline 28 & 48.82 & 29.5 & 66 & 56.31 & 20.0 & 104 & 48.48 & 24.0 \\
\hline 29 & 44.49 & 24.0 & 67 & 52.82 & 30.5 & 105 & 42.71 & 22.5 \\
\hline 30 & 49.00 & 28.0 & 68 & 42.39 & 22.5 & 106 & 46.10 & 23.5 \\
\hline 31 & 44.87 & 25.0 & 69 & 42.64 & 24.0 & 107 & 46.57 & 24.0 \\
\hline 32 & 45.58 & 22.5 & 70 & 39.40 & 12.5 & 108 & 29.50 & 11.0 \\
\hline 33 & 46.99 & 26.5 & 71 & 41.57 & 29.0 & 109 & 47.65 & 28.5 \\
\hline 34 & 41.12 & 17.5 & 72 & 46.46 & 27.0 & 110 & 44.43 & 22.5 \\
\hline 36 & 49.16 & 28.5 & 74 & 44.13 & 27.0 & 112 & 49.58 & 23.0 \\
\hline 37 & 51.06 & 29.5 & 75 & 45.92 & 26.0 & 113 & 48.26 & 29.0 \\
\hline 38 & 45.75 & 28.5 & 76 & 41.38 & 27.0 & 114 & 46.32 & 24.0 \\
\hline
\end{tabular}

Wide genetic variability for DMC has been reported in Africa [30] and the total phenotypic variation in DMC was due to genetic differences in an experiment with inbred and local cassava clones [5]. Thus the present study focused on QTL mapping to identify favourable alleles controlling the complex traits such as DMC and $\mathrm{SC}$, and is very much helpful in marker assisted selection. In this study, a genetic linkage map was constructed using 70 polymorphic SSR primer pairs. Each primer pairs were scored using single dose restriction fragment (SDRF) and the segregation pattern were studied using $\chi^{2}(p \leq 0.05)$. Ninety three $(82.3 \%)$ primers showed 1:1 disomic segregation pattern and twenty marker alleles (17.69\%) showed deviations from Mendelian segregation pattern. A genetic linkage map was constructed which comprises 24 linkage groups spanned a genetic distance of $1165.9 \mathrm{cM}$ and the random distribution of SSR markers throughout the genome were revealed through the correlation analysis $(\mathrm{r}=0.67)$ between linkage distance and numbers of markers in each linkage group [56].

QTLs controlling these complex quantitative traits were studied using different QTL mapping studies. SMA using simple linear regression identified seven marker alleles, which were found to be strongly associated with DMC viz., SSRY $21^{\mathrm{c}}, \mathrm{SSRY} 59^{\mathrm{c}}, \mathrm{SSRY} 59^{\mathrm{d}}, \mathrm{NS} 185^{\mathrm{c}}, \mathrm{NS} 185^{\mathrm{d}}, \mathrm{SSRY} 49^{\mathrm{c}}$ and SSRY $182^{\mathrm{b}}$ at $5 \%$ level of significance. On the other hand, eight marker alleles were found to be associated with SC viz., SSRY314 ${ }^{\mathrm{a}}, \mathrm{NS} 308^{\mathrm{b}}$, SSRY 59 ${ }^{\mathrm{c}}, \mathrm{SSRY} 59^{\mathrm{d}}$, SSRY $182^{\mathrm{b}}, \mathrm{NS}_{185^{\mathrm{c}}}$, $\mathrm{NS} 185^{\mathrm{d}}$ and SSRY $38^{\mathrm{d}}$ which was distributed in five linkage groups (Table 2). The distribution of markers controlling the DMC in different linkage group also explained the polygenic control of DMC. This is consistent with the studies of Kizito et al. [4] identified six QTLs controlling the DMC in four different linkage groups in cassava and also in favour of previous reports [25, 29]. QTLs controlling the root yield traits were studied by Okogbenin and Fregene [42] and Okogbenin et al. [44], root productivity and plant architecture [43] plant and first branch height, which were associated with root yield was reported by Boonchanawiwat et al., [6] and root yield and starch content [51].

Table 2. SSR markers associated with DMC and SC identified by SMA.

\begin{tabular}{|c|c|c|c|c|}
\hline Sl. No. & Linkage group & Markers & F-value of DMC & F-value of SC \\
\hline 1 & chrom6 & SSRY $21^{c}$ & $6.051^{*}$ & - \\
\hline 2 & chrom 14 & SSRY $314^{a}$ & - & $7.41 * *$ \\
\hline 3 & chrom 14 & $\mathrm{NS} 308^{\mathrm{b}}$ & - & $7.41 * *$ \\
\hline 4 & chrom 17 & SSRY59 ${ }^{\mathrm{c}}$ & $4.57^{*}$ & $7.58^{* *}$ \\
\hline 5 & chrom 17 & $\mathrm{NS} 185^{\mathrm{c}}$ & $4.57 *$ & $7.58 * *$ \\
\hline 6 & chrom 18 & SSRY59 ${ }^{d}$ & $4.57 *$ & $7.58 * *$ \\
\hline 7 & chrom 18 & $\mathrm{NS} 185^{\mathrm{d}}$ & $4.57^{*}$ & $7.58^{* *}$ \\
\hline 8 & chrom 20 & SSRY49 ${ }^{c}$ & $3.96^{*}$ & - \\
\hline 9 & Chrom 21 & SSRY $182^{b}$ & $6.196^{*}$ & $4.45^{*}$ \\
\hline 10 & chrom 24 & SSRY38 ${ }^{\mathrm{d}}$ & - & $8.93 * *$ \\
\hline
\end{tabular}

*,**- Probability at $5 \%$ and $1 \%$ level of significance respectively

In SMA, the association of single marker with that particular trait was revealed but the exact QTL positions, its effects and gene interaction were undetermined. This was made through interval mappings which scan the whole genome. Through SIM and CIM, a single QTL for DMC was identified in chrom 21 flanked by SSRY $110^{\mathrm{b}}$ and SSRY $182^{\mathrm{b}}$ (Table 3 and Figure 1). The exact position of the QTL was determined by MIM using MIM forward scan and was found at a position of $28 \mathrm{cM}$ in chrom 21 . On the other hand, five QTLs for SC were identified by SIM were distributed in five different linkage groups viz., chrom17, 18, 19, 21 and 24 at a
LOD value of 5 . The maximum $\mathrm{R}^{2}$ was $11 \%$ was explained by QTLs at chrom17, 18 and 24. The QTLs present in chrom 19 and 21 showed $\mathrm{R}^{2}$ values of $1 \%$ and $4 \%$ respectively (Table 4 and Figures 2, 3). Then CIM was performed to narrow down the QTL positions and identified a single QTL in chrom 17 with $\mathrm{R}^{2}$ value of $12 \%$ and at a LOD value 5 (Table 5 and Figure 4). The exact position, gene effects and gene interactions of the QTLs were analyzed by MIM and identified two main QTLs in chrom17 and chrom 18 present at $5 \mathrm{cM}$ and $22 \mathrm{cM}$ respectively (Table 6 ). 
Table 3. QTLs for DMC identified by CIM in Windows Cartographer 2.5 .

\begin{tabular}{|c|c|c|c|c|c|c|c|c|}
\hline QTLs & LG & Intervals & Additive effects (a) & Dominance Effects (d) & $\mathbf{d} / \mathbf{a}$ & Gene Action (GA) & LOD & $R^{2}$ value \\
\hline QTL1 & chrom 21 & $\operatorname{SSRY} 110^{\mathrm{b}}-\mathrm{SSRY} 182^{\mathrm{b}}$ & -1.04 & -13.22 & 12.7 & OD & 2.5 & $32 \%$ \\
\hline
\end{tabular}

Table 4. QTLs for SC identified by SIM in Windows Cartographer 2.5.

\begin{tabular}{|c|c|c|c|c|c|c|c|c|}
\hline QTLs & LG & Intervals & Additive effects (a) & Dominance Effects (d) & $\mathbf{d} / \mathbf{a}$ & Gene Action (GA) & LOD & $R^{2}$ value \\
\hline QTL1 & chrom 17 & SSRY $59^{\mathrm{c}}-\mathrm{NS} 185^{\mathrm{c}}$ & 1.07 & -12.18 & -11.38 & OD & $6 . .5$ & $11 \%$ \\
\hline QTL2 & chrom 18 & SSRY59 $9^{\mathrm{d}}-\mathrm{NS} 185^{\mathrm{d}}$ & -1.06 & -12.18 & 11.38 & OD & $6 . .5$ & $11 \%$ \\
\hline QTL3 & chrom19 & $\mathrm{SSRY} 35^{\mathrm{d}}-\mathrm{SSRY} 284^{\mathrm{c}}$ & 0.27 & -12.4 & -45.92 & OD & $5 . .6$ & $1 \%$ \\
\hline QTL4 & chrom 21 & $\operatorname{SSRY} 110^{\mathrm{b}}-\mathrm{SSRY} 182^{\mathrm{b}}$ & -0.35 & -12.4 & 35.43 & OD & $5 . .5$ & $4 \%$ \\
\hline QTL5 & chrom 24 & $\mathrm{NS} 158^{\mathrm{d}}-\mathrm{SSRY} 38^{\mathrm{d}}$ & -0.15 & -12.4 & 82.66 & OD & 5.10 & $11 \%$ \\
\hline
\end{tabular}

Table 5. QTLs for SC identified by CIM in Windows Cartographer 2.5 .

\begin{tabular}{lllllllll}
\hline QTLs & LG & Intervals & Additive effects (a) & Dominance Effects (d) & d/a & Gene Action (GA & LOD & $\mathbf{R}^{2}$ value \\
\hline QTL1 & chrom17 & ${\text { SSRY } 59^{c}-\mathrm{NS}_{185^{c}}}^{\mathrm{c}} 1.11$ & -11.43 & -10.29 & OD & 5.0 & $12 \%$ & \\
\hline
\end{tabular}

Table 6. QTLs for SC identified by MIM in Windows Cartographer 2.5.

\begin{tabular}{|c|c|c|c|c|c|c|c|}
\hline QTLs & LG & Intervals & Additive variance (A) & Dominance Variance (D) & QTL Pos cM & Interaction (AA) & $\mathbf{R}^{2}$ value \\
\hline QTL1 & chrom 17 & $\mathrm{SSRY} 59^{\mathrm{c}}-\mathrm{NS} 185^{\mathrm{c}}$ & 1.92 & -9.56 & 5 & \multirow{2}{*}{-3.58} & \multirow{2}{*}{$79 \%$} \\
\hline QTL2 & Chrom 18 & SSRY $59^{\mathrm{d}}-\mathrm{NS} 185^{\mathrm{d}}$ & 0.79 & -2.03 & 22 & & \\
\hline
\end{tabular}

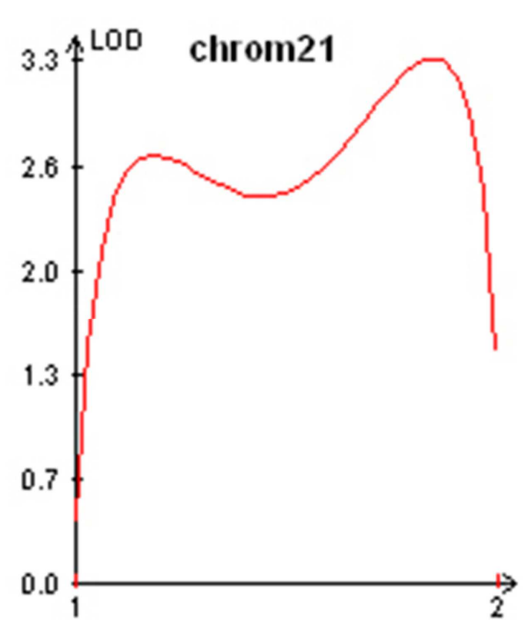

Figure 1. QTL for DM identified in chrom 21 using SIM and CIM.
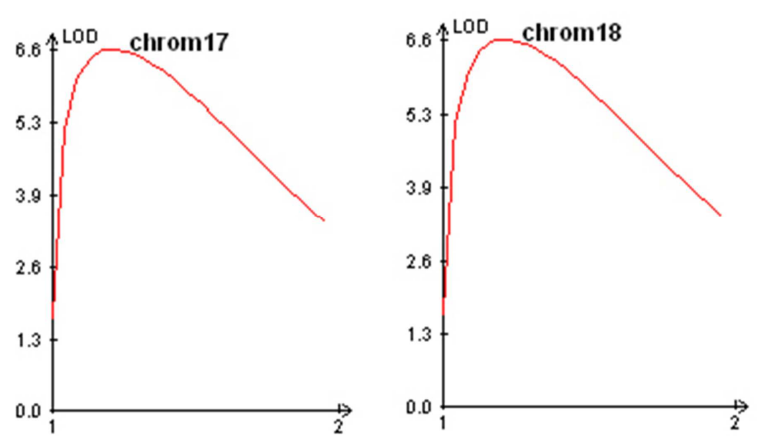

Figure 2. QTL associated with SC in chrom17 and chrom 18 using SIM.
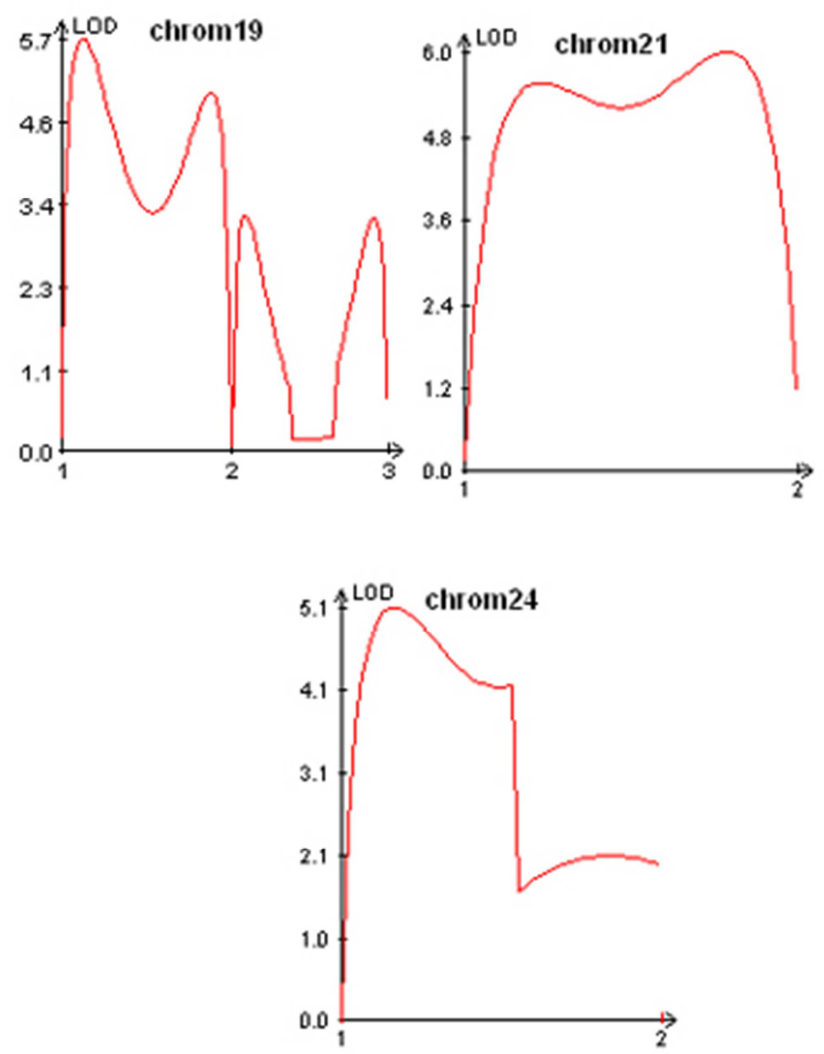

Figure 3. QTL associated with SC in chrom19, chrom 21 and chrom 24 using SIM. 


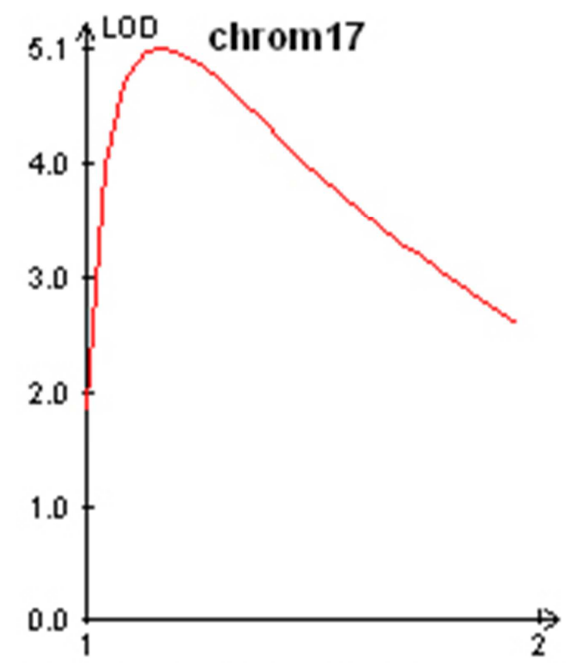

Figure 4. QTL associated with SC in chrom17 using CIM.

Important traits in crops were controlled by quantitative genes which have different actions [39]. Understanding the genetic architecture requires the decomposition of genetic effects into additive, dominance and epistatic components $[22,19,31]$. In the present study, the additive and dominant effects of the QTLs controlling DMC were found to be -1.04 and -13.22 respectively. Also the $\mathrm{R}^{2}$ value explained by these QTL was found to be $32 \%$. The genetic effect of QTLs controlling DMC was found to be over-dominance which was strongly supported by previous study conducted by Kizito et al. [33] and in that study, out of six QTLs identified for DMC, five QTLs showed dominance or over dominance and one QTL showed additive gene action. Amma et al. [3] and Amma and Sheela [2] also reported a non-additive gene control for dry matter and starch content using classical studies. On the other hand, Wolfe et al. [59], Kawano et al. [29] and IITA [25] reported polygenic additive control of root DMC in cassava. Several diallel studies in cassava indicated that non-additive genetic effects in root yield traits were strong [11, 10, 12, 28, 45, 46, 60, 34, 55, 14, 17]. In addition to cassava, non-additive effects were reported and utilized in the breeding of potato [32], Eucalyptus [49] and loblolly pine [40]. A few attempts that have been made to understand the genetics of starch and starch-related traits in cassava that had been reported to be polygenically controlled. There is a positive correlation exist between DMC and SC. The interaction between the QTLs controlling SC was studied and identified a strong additive $\mathrm{x}$ additive epistatic (AA) interaction between QTLs. The $\mathrm{R}^{2}$ value explained by QTL interaction was found to be $79 \%$. The total phenotypic and genotypic variance explained by the trait was found to be 19.59 and 15.64 respectively.

Non-additive variations are common in cassava, especially for low heritability traits. In the present study, the $\mathrm{H}^{2}$ of DMC was found to be $32.7 \%$. The $\mathrm{H}^{2}$ and $\mathrm{h}^{2}$ of this QTL interaction was calculated and found to be $79.8 \%$ and $43 \%$ respectively. The $\mathrm{H}^{2}$ and $\mathrm{h}^{2}$ of this QTL interaction was calculated and found to be $79.8 \%$ and $43 \%$ respectively. The genetic gain from the selection was found to be 3.35 . The non-additive variation also explained the slow genetic gain in cassava [13] and low accuracies have been reported for genomic prediction of yield compared with CMD resistance and DMC [20, 38]. Inbreeding to convert dominance variance to additive and better control epistatic combinations, as in maize has been suggested as a solution to non-additive genetics [14]. Moreover, the moderate broad sense heritabilities of root yield and starch content inferred that these traits were strongly influenced by the environment [50]. Such traits were expected to be difficult to handle by direct selection [41].

Generally, QTL underlying related traits tend to map in the same genomic regions or adjacent regions in the same linkage group [52]. Therefore, QTL for yield and yield associated traits such as yield components (starch content, \% dry matter, seed number and seed weight) and yield-related traits (plant architecture, biomass and harvest index) appeared to be clustered in the genome [48]. In the present study, it was also found that five QTLs identified by SMA and single QTL from interval mapping were common to both DMC and SC. The QTL affecting different traits within the same genomic regions could be explained by pleiotropic effects or the close linkage of multiple genes [43]. The major indicators for pleiotropic QTL were overlapped confidence interval regions of separate QTL, trait correlations and environmental correlations [54]. The consistent QTL and the coincident QTL controlling different traits should be useful for MAS [59, 47]. Thus the genetic variation in root yield trait such as DMC and SC in cassava was greatly explained by the genetic effects (additive and dominance). Performance of best hybrid therefore depends mainly on additive and dominant variance but gets an extra boost from epistasis. In a clonally propagated crop such as cassava, non-additive genetic effects can be effectively exploited by the identification of superior genetic individuals as varieties.

\section{Conclusion}

This study focused to identify QTLs controlling the traits such as SC and DMC in cassava. The study is conducted using the statistical package Windows cartographer version 2.5. The genetic effect of QTLs controlling DMC was found to be over-dominance and that of $\mathrm{SC}$ was found to be additive $\mathrm{x}$ additive epistatic interaction.

\section{Acknowledgements}

The authors would like to express their sincere thanks to The Director, ICAR-CTCRI for providing all the necessary facilities and field for the successful completion of the work. Also express thank to UGC (University Grant Commission) for providing financial assistance.

\section{References}

[1] Aigbe SO and Remison SU (2010). The influence of root rot on starch content of cassava planted in different ecological environment of Nigeria. Nigerian Annals of Natural Sciences 10 (1): $60-70$ 
[2] Amma CSE and Sheela MN (1998). Genetic analysis in a diallel cross of inbred lines of cassava. Madras Agricultural Journal 85: 64-268.

[3] Amma CSE, Sheela MN and Pillai PKT (1995). Combining ability heterosis and gene action for three major quality traits in cassava. Journal of Root Crops 21: 24-29.

[4] Asare PA. 2004. Determination of dry matter content in cassava tubers. B. Sc. dissertation. University of Cape Coast, Cape Coast, Ghana. pp. 34.

[5] Benesi IRM, Labuschagne MT, Dixon AGO and Mahungu NM (2004). Stability of native starch quality parameters, starch extraction and root dry matter of cassava genotypes in different environments. Journal of the Science of Food and Agriculture 84: 1381-1388.

[6] Boonchanawiwat A, Sraphet S, Boonseng O, Lightfoot D and Triwitayakorn K (2011). QTL underlying plant and first branch height in cassava (Mahihot esculenta Crantz). Field Crops Research 121: 343-349. doi: 10.1016/j.fcr.2010.12.022.

[7] Bright BP, Elizabeth P, Joseph M-A, Peter K, Angeline van B and Maryke L (2020). Genetic variability, stability and heritability for quality and yield characteristics in provitamin A cassava varieties. Euphytica 216: 31

[8] Burns A, Gleadow R, Cliff J, Zacarias A and Cavagnaro T (2010). Cassava: The Drought, War and Famine Crop in a Changing World. Sustainability 2: 3572-3607. doi: $10.3390 / \mathrm{su} 2113572$.

[9] Byrne D (1984). Breeding cassava. Plant Breeding Reviews 2: 73-133.

[10] Cach NT, Lenis JI, Perez JC, Morante N, Calle F and Ceballos $\mathrm{H}$ (2006). Inheritance of useful traits in cassava grown in subhumid conditions. Plant Breeding 125: 177-182.

[11] Cach NT, Perez JC, Lenis JI, Calle F, Morante N and Ceballos $\mathrm{H}$ (2005). Epistasis in the expression of relevant traits in cassava (Manihot esculenta Crantz) for subhumid conditions. Journal of Heredity 96 (5): 586-592. doi: https://doi.org/10.1093/jhered/esi084.

[12] Calle F, Perez JC, Gaitán W, Morante N, Ceballos H, Llano G and Alvarez E. 2005. Diallel inheritance of relevant traits in cassava (Manihot esculenta Crantz) adapted to acid-soil savannas. Euphytica 144 (1): 177-186. doi: 10.1007/s10681005-5810-y.

[13] Ceballos H, Hershey C and Becerra-López-Lavalle LA (2012). New approaches to cassava breeding. Plant Breeding Reviews 36: 427-504.

[14] Ceballos H, Kawuki RS, Gracen VE, Yencho GC and Hershey CH (2015). Conventional breeding, marker-assisted selection, genomic selection and inbreeding in clonally propagated crops: a case study for cassava. Theoretical and Applied Genetics 128: 1647-1667.

[15] Ceballos H, Jaramillo JJ, Salazar S, Pineda LM, Calle F and Setter T (2017). Induction of flowering in cassava through grafting. Journal of Plant Breeding and Crop Science 9 (2): 19-29. DOI: $10.5897 / J P B C S 2016.0617$.

[16] Cervantes JC, Sosinski B, Pecota KV, Mwanga ROM, Catignani GL, Truong VD, Watkins RH, Ulmer MR, Yencho GC (2011). Identification of quantitative trait loci for dry matter, starch and $\beta$-carotene content in sweet potato.
Molecular Breeding 28: 201-216. DOI 10.1007/s11032-0109474-5.

[17] Chalwe A, Melis R, Shanahan P and Chiona M (2015). Inheritance of resistance to cassava green mite and other useful agronomic traits in cassava grown in Zimbia. Euphytica 205 (1): 103-119. doi: 10.1007/s10681-015-1404-5

[18] Charles AL, Sriroth K and Tozou-chi H (2005). Proximate composition, mineral contents, hydrogen cyanide and phytic acid of 5 cassava genotypes. Food Chemistry 92 (4): 615-620.

[19] Cockerham CC (1954). An extension of the concept of partitioning hereditary variance for analysis of covariances among relatives when epistasis is present. Genetics 39 (6): $859-882$

[20] de Oliveira EJ, Resende MD V, Silva SV, Ferreira CF, Oliveira GAF, da Silva MS, de Oliveira LA and Aguilar-Vildoso CI (2012). Genome wide selection in cassava. Euphytica 187: 263-276.

[21] FAOSTAT (2018). Food and Agricultural Commodities Production.

[22] Fisher RA (1918). The correlation between relatives on the supposition of mendelian inheritance. Transactions of the Royal Society of Edinburgh archives 52: 399-433.

[23] Fuglie KO, Oates CG and Xie J (2006). Root Crops, starch and agro-industrialization in Asia, Social Sciences Working Paper Series No. 2006-3. International Potato Center. (Peru: CIP) 19.

[24] Hahn SK, John C, Isoba $G$ and Ikohun $T$ (1989). Resistance breeding in root crops at International Institute of Tropical Agriculture (IITA), Ibadan, Nigeria. Crop Protection 8: 147-168.

[25] IITA (1985). Cassava in Tropical Africa. A reference Manual. International Institute of Tropical Agriculture, Ibadan, Nigeria. pp. 12-13, 24-25.

[26] Jansen PC (1993). Interval mapping of multiple quantitative trait loci. Genetics 135: 205-211.

[27] Jansen RC and Stam P (1994). High resolution of quantitative traits into multiple loci via interval mapping. Genetics 136: 1447-1455.

[28] Jaramillo G, Morante N, Pérez JC, Calle F, Ceballos H, Arias B and Bellotti AC (2005). Diallel analysis in cassava adapted to the midaltitude valleys environment. Crop Science 45: 1058-1063.

[29] Kawano K, Fukuda WMG and Cenpukdec U (1987). Genetic and environmental effects on dry matter content of cassava root. Crop science 27: 69-74.

[30] Kawuki RS, Ferguson M, Labuschagne M, Herselman L, Orone J, Ralimanana I, Bidiaka M, Lukombo S, Kanyange MC, Gashaka G, Mkamilo G, Gethi J and Obiero H (2011). Variation in qualitative and quantitative traits of cassava germplasm from selected national breeding programmes in sub-Saharan Africa. Field Crops Research 122 (2): 151-156. doi: 10.1016/j.fcr.2011.03.006.

[31] Kempthorne O (1954). The correlation between relatives in a random mating population. Proceedings of Royal Society of London B: Biological Sciences 143: 103-113. doi: 10.1098/rspb.1954.0056. 
[32] Killick RJ (1977). Genetic analysis of several traits in potatoes by means of a diallel cross. Annals of Applied Biology 86 (2): 279-289. doi: 10.1111/j.1744-7348.1977.tb01841.x.

[33] Kizito EB, Chiwona-Karltun L, Egwang T, Fregene M and Westerbergh A (2007). Genetic diversity and variety composition of cassava on small scale farms in Uganda: an interdisciplinary study using genetic markers and farmer interviews. Genetics 130 (3): 301-318. doi: 10.1007/s10709006-9107-4.

[34] Kulembeka HP, Ferguson M, Herselman L, Kanju E, Mkamilo G, Masumba E, Fregene M and Labuschagne MT (2012). Diallel analysis of field resistance to brown streak disease in cassava (Manihot esculenta Crantz) landraces from Tanzania. Euphytica 187: 277-288. doi: 10.1007/s10681-0120730-0.

[35] Lander ES and Botstein D (1989). Mapping Mendelian factors underlying quantitative traits using RFLP linkage maps. Genetics 121 (1): 185-199.

[36] Lian SL (1985). Selection for yield potential. In: Cassava: Research, Production and Utilization (Eds. Cork JH, Reyes JA). Cali, Columbia: UNDP/CIAT.

[37] Lincoln S, Dalyand M and Lander E (1993). Constructing genetic Linkage maps with MAPMAKER/EXP Version 3.0: A Tutorial and Reference Manual. Whitehead Institute Technical Report. Whitehead Institute for Biomedical Research/MIT Center for Genome Research, Cambridge, MA.

[38] Ly D, Hamblin M, Rabbi I, Melaku G, Bakare M, Hugh G. Gauch Jr. HG, Okechukwu R, Dixon AGO, Kulakow P and Jannink JL (2013). Relatedness and genotype $\times$ environment interaction affect prediction accuracies in genomic selection: a study in cassava. Crop Science 53: 1312.

[39] Mitra J (2001). Genetics and genetic improvement of drought resistance in crop plants. Current Science 80 (6): 758-763.

[40] Muñoz PR, Resende MFR, Gezan SA, Resende MDV, de los Campos G, Kirst M and Peter GF (2014). Unraveling additive from non-additive effects using genomic relationship matrices. Genetics 198: 1759-1768.

[41] Ntawuruhunga P and Dixon AGO (2010). Quantitative variation and interrelationship between factors influencing cassava yield. Journal of Applied Biosciences 26: 1594-1602.

[42] Okogbenin E and Fregene M (2002). Genetic analysis and QTL mapping of early root bulking in an $F_{1}$ population of non-inbred parents in cassava (Manihot esculenta Crantz). Theoretical and Applied Genetics 106 (1): 58-66. doi: 10.1007/s00122-002-1068-0.

[43] Okogbenin E and Fregene M (2003). Genetic mapping of QTLs affecting productivity and plant architecture in a full-sib cross from non-inbred parents in cassava (Manihot esculenta Crantz). Theoretical and Applied Genetics 107 (8): 1452-1462. doi: $10.1007 / \mathrm{s} 00122-003-1383-0$.

[44] Okogbenin E, Marin J and Fregene M (2008). QTL analysis for early yield in a pseudo $F_{2}$ population of cassava. African Journal of Biotechnology 7 (2): 131-138.

[45] Pérez JC, Ceballos H, Calle F, Morante N, Gaitán W, Llano G and Álvarez E (2005a). Within-family genetic variation and epistasis in cassava (Manihot esculenta Crantz) adapted to the acid soils environment. Euphytica 145: 77-85.
[46] Pérez JC, Ceballos H, Jaramillo G, Morante N, Calle F, Arias B and Bellotti AC (2005b). Epistasis in cassava adapted to midaltitude valley environments. Crop Science 45: 1491-1496.

[47] Redoña ED and Mackill DJ (1998). Quantitative trait locus analysis for rice panicle and grain characteristics. Theoretical and Applied Genetics 96 (6): 957-963. doi: $10.1007 / \mathrm{s} 001220050826$.

[48] Shi J, Li R, Qiu D, Jiang C, Long Y, Morgan C, Bancroft I, Zhao J and Meng J (2009). Unraveling the complex trait of crop yield with quantitative trait loci mapping in Brassica napus. Genetics 182 (3): 851-861. doi: 10.1534/genetics.109.101642.

[49] Silva CEJ, Borralho NM and Potts BM (2004). Additive and non-additive genetic parameters from clonally replicated and seedling progenies of Eucalyptus globulus. Theoretical and Applied Genetics 108 (6): 1113-1119. doi: 10.1007/s00122003-1524-5.

[50] Song X, Han Y, Teng W, Sun G and Li W (2010). Identification of QTL underlying somatic embryogenesis capacity of immature embryos in soybean (Glycine max (L.) Merr.). Plant Cell Reports 29 (2): 125-131. doi: 10.1007/s00299-009-0804-1.

[51] Sraphet S, Boonchanawiwat A, Thanyasiriwat TR, Thaikert R, Whankaew S, Smith DR, Boonseng O and Lightfoot D A, Triwitayakorn K (2016). Quantitative trait loci underlying root yield and starch content in an $\mathrm{F}_{1}$ derived cassava population (Manihot esculenta Crantz). Journal of Agricultural Science 113. doi: $10.1017 / \mathrm{S} 0021859616000678$.

[52] Sun XY, Wu K, Zhao Y, Kong FM, Han GZ, Jiang HM, Huang XJ, Li RJ, Wang HG and Li SS (2009). QTL analysis of kernel shape and weight using recombinant inbred lines in wheat. Euphytica 165: 615-624. doi: 10.1007/s10681-0089794-2.

[53] Teye E, Asare AP., Amoah RS. and Tetteh JP (2011). Determination of the dry matter content of cassava (Manihot esculenta Crantz) tubers using specific gravity method. ARPN Journal of Agricultural and Biological Science 6 (11): 23-28

[54] Timmerman-vaughan GM, Mills A, Whitfield C, Frew T, Butler R, Murray S, Lakeman M, Mccallum J, Russell A and Wilson D (2005). Linkage mapping of QTL for seed yield, yield components, and developmental traits in pea. Crop Science 45: 1336-1344.

[55] Tumuhimbise R, Melis R and Shanahan P (2014). Diallel analysis of early storage root yield and disease resistance traits in cassava (Manihot esculenta Crantz). Field Crops Research 167: 86-93.

[56] Vidya P, 2020, Aswathy GH Nair, Mohan C, Sreekumar J and Ambu V (2020). Construction of SSR Based Genetic Linkage Map and Identification of QTLs Conferring CMD Resistance in Cassava. International Journal of Bio-resource and Stress Management 2020, $11 \quad$ (4), 387-397. DOI. ORG/10.23910/1.2020.2135

[57] Wanatsanan S, Saowalak K, Malinee S, Supatcharee N, Asawin M, Treenut S (2012). Transcriptomic data integration inferring the dominance of starch biosynthesis in carbon utilization of developing cassava roots. Procedia Computer Science 11: 96-106. 
[58] Wolfe MD, Kulakow P, Rabbi IY and Jannink JL (2016). Marker-Based Estimates Reveal Significant nonadditive effects in clonally propagated cassava (Manihot esculenta): Implications for the prediction of total genetic value and the selection of varieties. Genes/Genomes/Genetics 6 (11): $3497-$ 3506. doi: 10.1534/g3.116.033332.

[59] Xiao J, Grandillo S, Ahn SN, Mccouch SR, Tanksley SD, LI J and Yuan L (1996). Genes from wild rice improve yield. Nature 384: 223-224. doi: 10.1038/384223a0.

[60] Zacarias M and Labuschagne MT (2010). Diallel analysis of cassava brown streak disease, yield and yield related characteristics in Mozambique. Euphytica 176 (3): 309-320. doi: 10.1007/s10681-010-0203-2.

[61] Zeng ZB (1993). Theoretical basis of separation of multiple linked gene effects on mapping quantitative trait loci. Proceedings of the National Academy of Sciences 90 (23): 10972-10976.

[62] Zeng ZB (1994). Precision mapping of quantitative trait loci. Genetics 136 (4): 1457-1468. 